\title{
Sensitivity Analysis for Aerosol Refractive Index and Size Distribution Estimation Methods Based on Polarized Atmospheric Irradiance Measurements
}

\author{
Kohei Arai ${ }^{1}$ \\ ${ }^{1}$ Graduate School of Science and Engineering \\ Saga University \\ Saga City, Japan
}

\begin{abstract}
Aerosol refractive index and size distribution estimations based on polarized atmospheric irradiance measurements are proposed together with its application to reflectance based vicarious calibration. A method for reflectance based vicarious calibration with aerosol refractive index and size distribution estimation using atmospheric polarization irradiance data is proposed. It is possible to estimate aerosol refractive index and size distribution with atmospheric polarization irradiance measured with the different observation angles (scattering angles). The Top of the Atmosphere (TOA) or atsensor radiance is estimated based on atmospheric codes with estimated refractive index and size distribution then vicarious calibration coefficient can be calculated by comparing to the acquired visible to near infrared instrument data onboard satellites. The estimated TOA radiance based on the proposed method is compared to that with aureole-meter based approach which is based on refractive index and size distribution estimated with solar direct, diffuse and aureole (Conventional AERONET approach). It is obvious that aureole-meter is not portable, heavy and large while polarization irradiance measurement instruments are light and small (portable size and weight).
\end{abstract}

Keywords-Degree of Polarization; aerosol refractive index; size distribution

\section{INTRODUCTION}

Earth observation satellites have a long history of being characterized by vicarious methods. These include the Marine Observation Satellite-1 [Arai, 1988], Landsat-7 Enhanced Thematic Mapper Plus [Barker, et al., 1999], SeaWiFS [Barnes, et al., 1999], SPOT-1 and 2 [Gelleman, et al., 1993], Hyperion [Folkman, et al., 1997], and POLDER [Hagolle, et al., 1999]. Vicarious approaches also provide a crosscomparison between sensors to characterize mission instruments onboard the same satellite [Arai, 1997] via the use of well-understood ground areas such as desert sites [Cosnefroy, et al., 1996]. Arai and Thome [2000] published an error budget analysis of solar reflectance-based vicarious calibration. The most dominant factor for vicarious calibration is surface reflectance measurement, followed by optical depth measurement, estimation of refractive index, aerosol size distribution, and identification error in test site pixels. Typical vicarious calibration accuracy is around 4\%. Onboard calibrators cannot provide results of a higher accuracy than the preflight laboratory calibration. This means that the accuracy of the in-flight (absolute) calibration is inferior to the preflight results. This is because the preflight calibration source is used to calibrate the onboard calibrators. In addition, the uncertainty of the onboard calibrator typically increases with time. Hence, it makes good sense to include additional calibration approaches that are independent of the preflight calibration. Besides the normal and expected degradation of the onboard calibrators, they also run the risk of failing or operating improperly. Therefore, vicarious approaches are employed to provide further checks on the sensor's radiometric behavior. Given the understanding that the orbiting sensor's response will change over time, the ASTER science team developed a methodology, based on OBC results, to update preflight RCCs that are input to generate the Level1B product [Thome, Arai et al., 2008]. The OBC results are also combined with vicarious calibration to produce the most accurate knowledge of ASTER's radiometric calibration.

The solar radiometers are relatively calibrated immediately prior to, during, or after each field campaign via the Langley method or Modified Langley method, and this allows for the determination of spectral atmospheric optical depths [Arai, et al., 2005]. The optical depth results are used as part of an inversion scheme to determine ozone optical depth and an aerosol size distribution. The aerosols are assumed to follow a power law distribution, also referred to as a Junge distribution. Columnar water vapor is derived from the solar extinction data using a modified-Langley approach. The atmospheric and surface data are used in a radiative transfer code. There are a variety of codes available that satisfy all the requirements of predicting the at-sensor radiance to the required accuracy. It has shown that similar conclusions are drawn for other code types such as doubling-adding, and the methods used in the $6 \mathrm{~S}$ code [Lenoble 1985]. Besides these, another method takes into account polarizations in the calculation of down-welling and up-welling radiation [Arai et al., 2003]. It uses groundbased solar direct, diffuse and aureole radiance measurements as well as polarized radiance with several polarization angles [Arai and Liang, 2005, and Liang and Arai, 2005]. It is obvious that aureole-meter is not portable, heavy and large while polarization irradiance measurement instruments are light and small (portable size and weight). This study is based on a Lambertian view of the surface. The near-nadir view for the majority of the ASTER overpasses reduces the uncertainty of this assumption since the dominant direct-reflected solar 
irradiance is correctly taken into account. Strong gaseous absorption effects due to water vapor are determined using MODTRAN to compute transmittance for the sun-to-surfaceto-satellite path for 1-nm intervals from 350 to $2500 \mathrm{~nm}$. Also ozone absorption is taken into account based on MODTRAN with measured column ozone using atmospheric extinction measurements. This sun-to-ground-to-sensor transmittance is multiplied by the at-sensor radiance output from the radiative transfer code to correct the radiances for this strong absorption. While this approach is an approximation that excludes interactions between diffusely scattered radiances and absorption, it does not cause large uncertainties for ASTER applications because of the small absorption effect within most of the bands, and the typically high surface reflectance of the test sites used in this work.

For the multiple-scattering components calculation, it is easy to estimate Rayleigh scattering (molecule) with measured atmospheric pressure. Meanwhile Mie scattering (aerosol) is not so easy to estimate. Aerosol parameters, refractive index, size distribution, etc. have to be estimated. AERONET (Holben B.N. et al., 1998) and SKYNET Aoki, K. et al., 2005) allows for the estimation of aerosol parameters at the specific locations. They use aureole-meters and sky-radiometers which allow solar direct, diffuse and aureole irradiance. These ground-based instruments are heavy and large so that they equip them at the specific sites. Small and light portable polarization irradiance measuring instrument, on the other hand, is proposed by Arai (2009) for estimation of aerosol parameters. With a measured polarized irradiance at the specific observation angles (scattering angles) allows estimation of aerosol refractive index and size distribution. Estimated aerosol parameters are a little bit differing from those which are derived from AERONET as well as SKYNET. This paper describes at-sensor radiance of ASTER/VNIR with the estimated aerosol parameters derived from AERONET and SKYNET as well as the proposed method together with a sensitivity analysis.

\section{PROPOSED MODEL}

Reflectance based vicarious calibration method proposed here is based on MODTRAN with the following input parameters, Measured surface reflectance (Lambertian surface), Calculated molecule scattering based on a measured atmospheric pressure, Calculated aerosol scattering with the aerosol parameters, refractive index and size distribution which are estimated with measured polarized irradiance at several scattering angles (for instance seven scattering angles which ranges from 60 to 120 with 10 degree step) based on the proposed method, Calculate absorbance due to water vapor and ozone with measured column water and ozone.

At-sensor radiance is estimated based on MODTRAN and is compared to the actual ASTER/VNIR data derived radiance. The most influencing factor of the proposed method is estimation accuracy of aerosol parameters, refractive index and size distribution.

Therefore, sensitivity of aerosol parameters on TOA radiance should be analyzed. Figure 1 shows the calculated TOA radiance in unit of $\left[\mathrm{W} / \mathrm{cm}^{2} / \mathrm{sr} / \mu \mathrm{m}\right]$ with the parameter of real and imaginary parts of refractive index while Figure 2 shows the calculated TOA radiance with the parameters of size distribution.
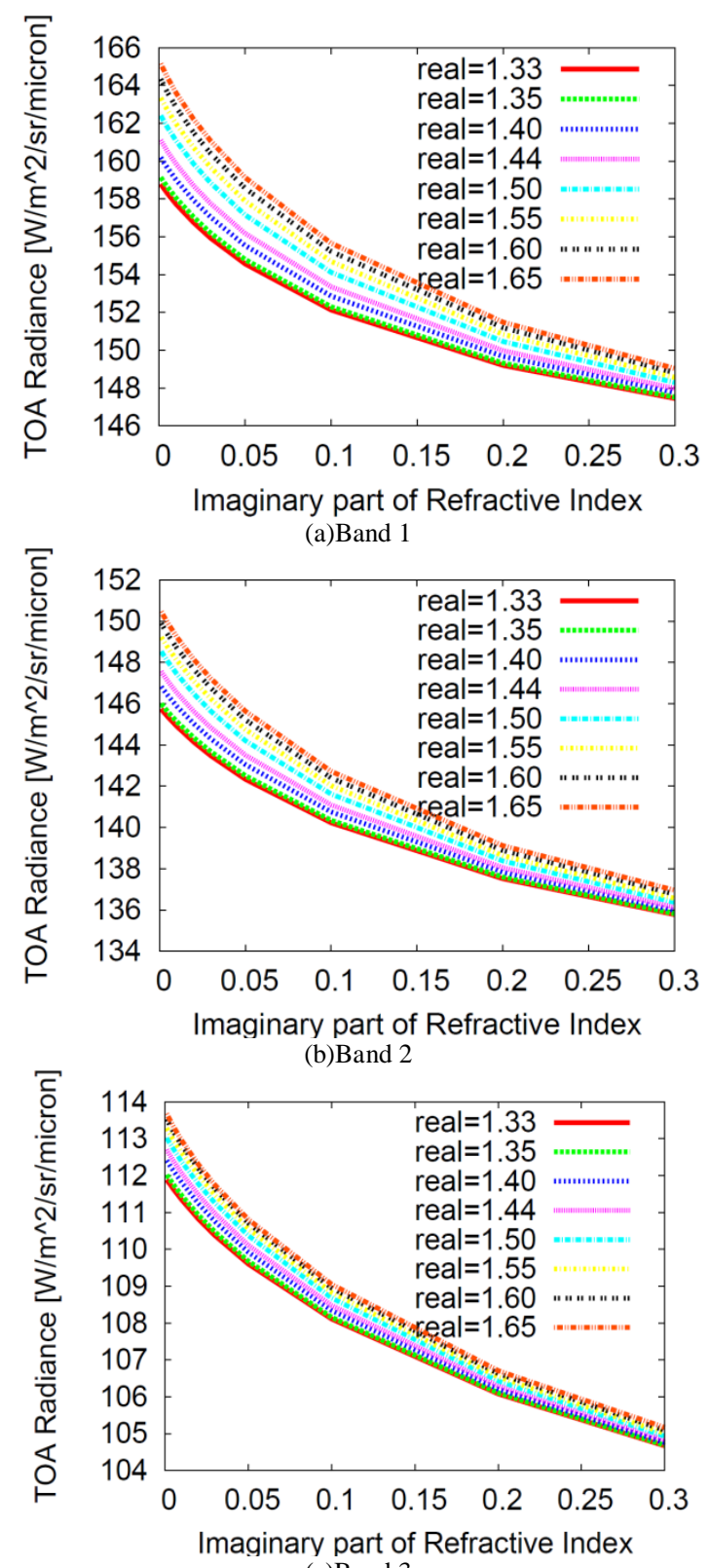

(c)Band 3

Fig. 1. Calculated TOA radiance derived from the field campaign which was conducted at Railroad valley on September 212008 with the parameters of real and imaginary parts of refractive index. 

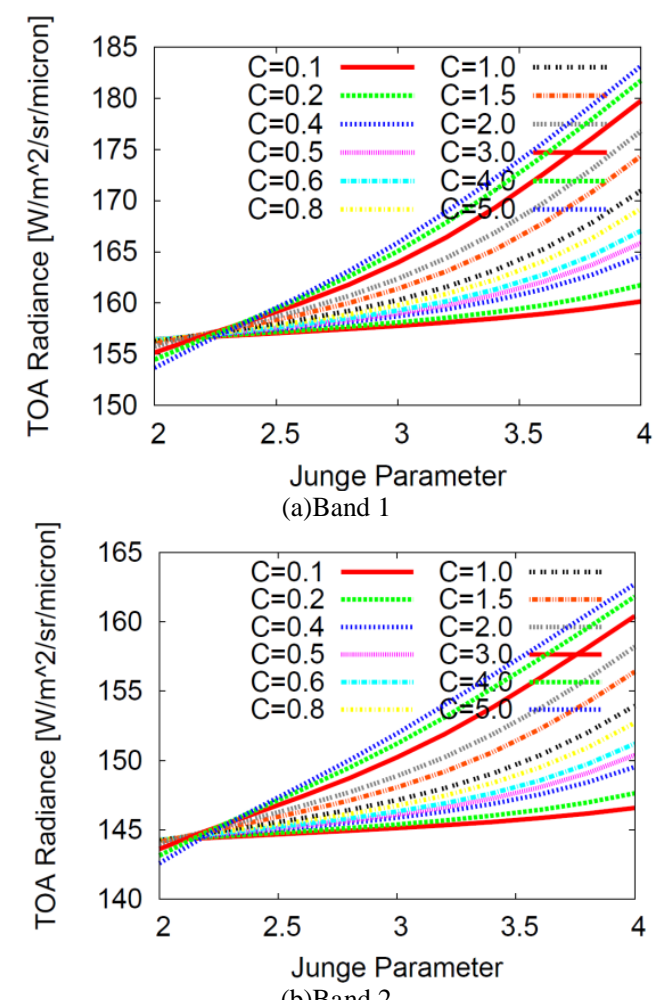

(b)Band 2

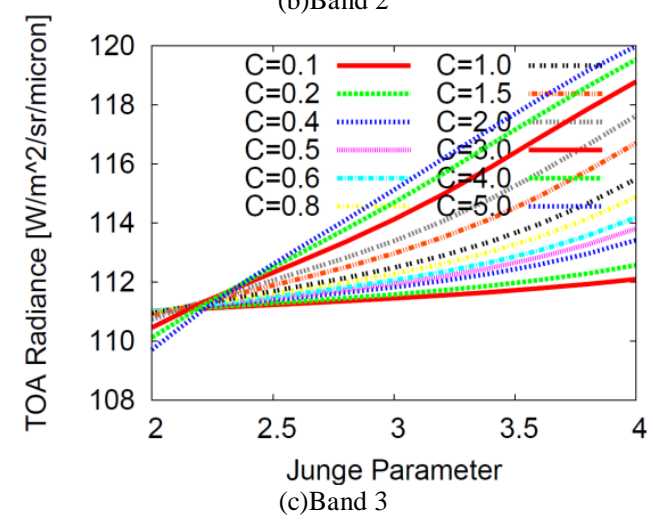

Fig. 2. TOA radiance as a function of Junge parameter

These examples are derived from the field campaign which was conducted at Railroad valley on September 212008. Junge distribution, one of power low distributions is assumed as is expressed as the equation (1).

$$
\frac{d N}{d \ln (r)}=C r^{-\alpha}, \alpha=-(v+1)
$$

where $\alpha$ denotes the slope of the relation between volume and radius of aerosol particles and $v$ is Junge parameter as are shown in Figure 3. Figure 3 also shows a typical aerosol density vertical profile. TOA radiance is increased with increasing of real part of refractive index and is decreased with increasing of imaginary part of refractive index. The TOA radiance-increasing ratio at shorter wavelength (Band 1) is much greater than that in the longer wavelength (Band $3 \mathrm{~N}$ : Nadir view). Figure 1 and 2 also show that the calculated TOA radiance is changed below $2 \%$ when the estimated refractive index and Junge parameter are changed within a range of $\pm 10 \%$ from the assumed typical values, 1.44 of real part of refractive index, 0.05 of imaginary part of refractive index and 3 of Junge parameter. This implies that required estimation accuracy of refractive index and size distribution is not so high; about $\pm 10 \%$ would be enough if $2 \%$ were the required TOA radiance estimation accuracy.

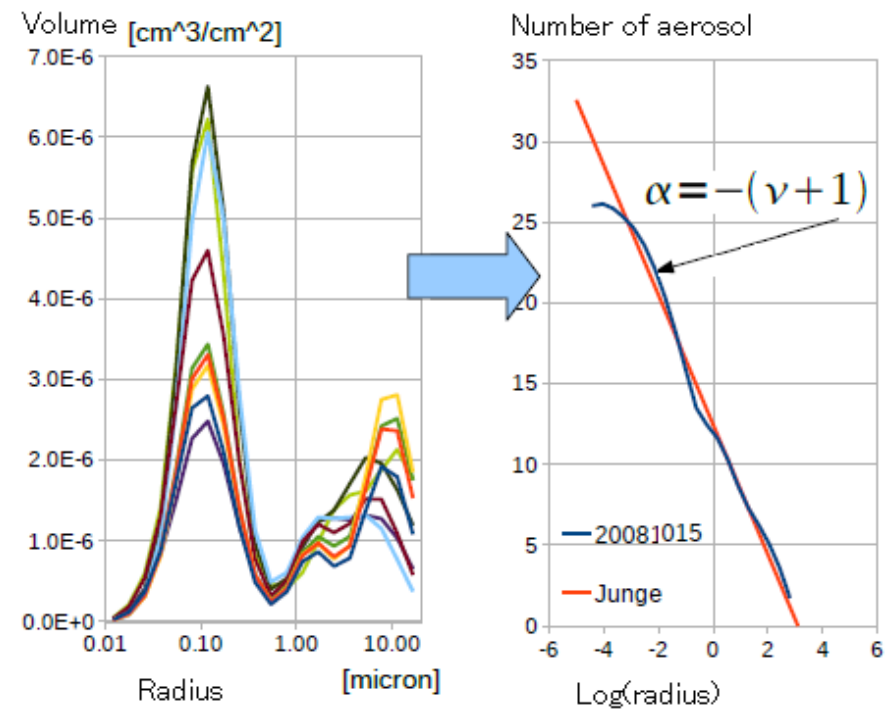

(a) Volume spectrum, Size distribution (b) Number of aerosol particle

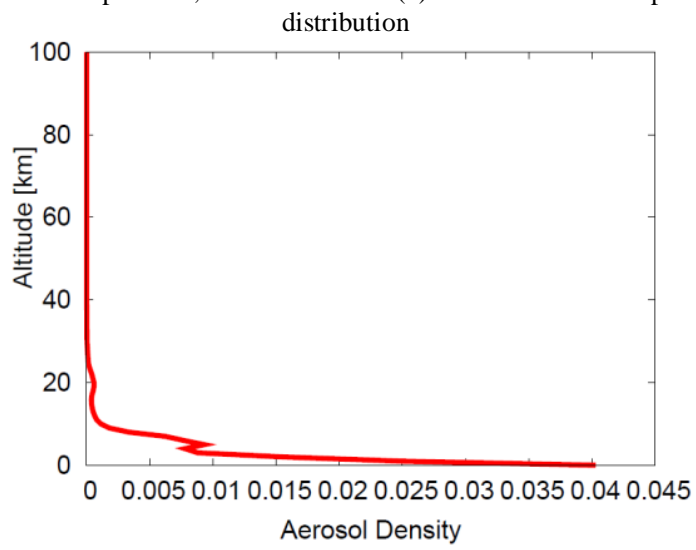

(c) Vertical profile of aerosol density

Fig. 3. Volume spectrum and corresponding power low distribution, representation of aerosol size distribution with Junge parameter with corresponds to slope of the power low distribution together with aerosol density profile (an example of Saga $(33: 14.46 \mathrm{~N}, 130: 17.3 \mathrm{E}, 29 \mathrm{~m}$ ) field campaign which was conducted on October 15 2008).

\section{EXPERIMENTL}

Field campaigns were conducted at Roach Lake on December 32008 and at Coyote Lake on December 10 2008, respectively. Table 1 shows the detailed information of the field campaigns.

Measured column ozone and water vapor are shown in Figure 4 (a) while relation between $\ln$ (wavelength) and $\ln$ (optical depth) are shown in Figure 4 (b), respectively. Also measured surface reflectance as well as estimated refractive index and size distribution are shown in Figure 4 (c) to (f). These are measured and estimated values for Roach Lake field campaign that was conducted on December 32008. 
TABLE I. DETAILED INFORMATION OF THE FIELD CAMPAIGNS CONDUCTED.

\begin{tabular}{|l|l|l|}
\hline Date and time (UTM) & $\begin{array}{l}\text { December 3 } \\
2008, \\
18: 38: 34\end{array}$ & $\begin{array}{l}\text { December 10 } \\
2008,18: 38: 34\end{array}$ \\
\hline Solar azimuth and zenith angles & $154.48,59.84$ & $163.92,59.61$ \\
\hline Location & $\begin{array}{l}\text { Roach } \\
\text { Lake(38:30:1 } \\
8 \mathrm{~N}, 115: 41: 29 \\
\text { W) }\end{array}$ & $\begin{array}{l}\text { Coyote } \\
\text { Lake(35:03:53 } \\
\text { N,116:44:50W }\end{array}$ \\
\hline Air-temperature, atmospheric pressure & $22.5,933 \mathrm{hPa}$ & $22.1,974 \mathrm{hPa}$ \\
\hline Junge parameter(370/870, 500/870) & $2.73,3.15$ & $5.89,7.21$ \\
\hline Ozone(DU), Water vapor $\left(\mathrm{g} / \mathrm{cm}^{\wedge} 2\right)$ & $284.7,0.24$ & $271.6,0.46$ \\
\hline
\end{tabular}

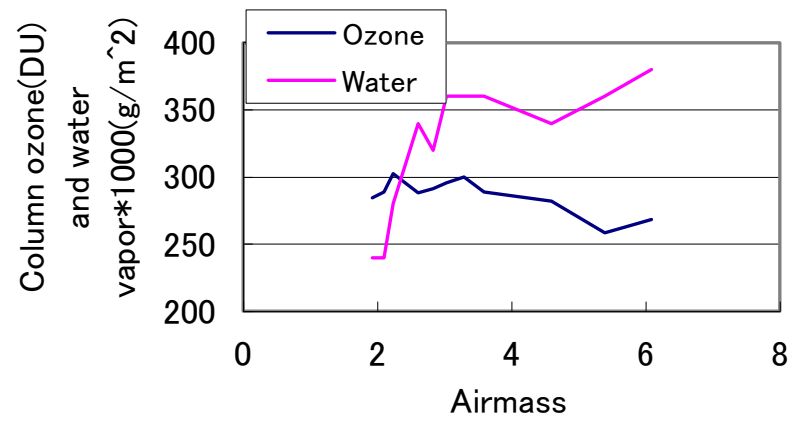

(a) Column ozone and water vapor

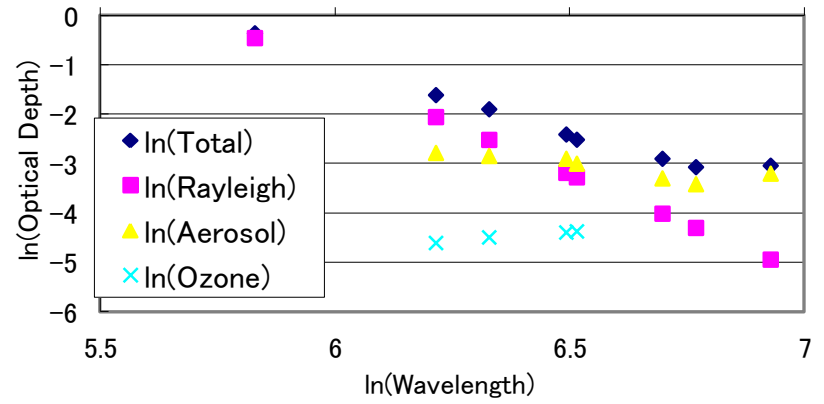

(b) Angstrome exponent and Junge parameter

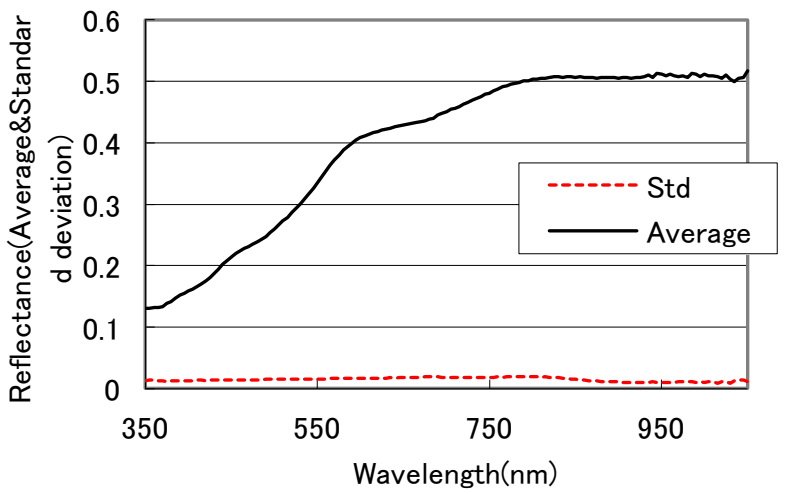

(c) Surface reflectance

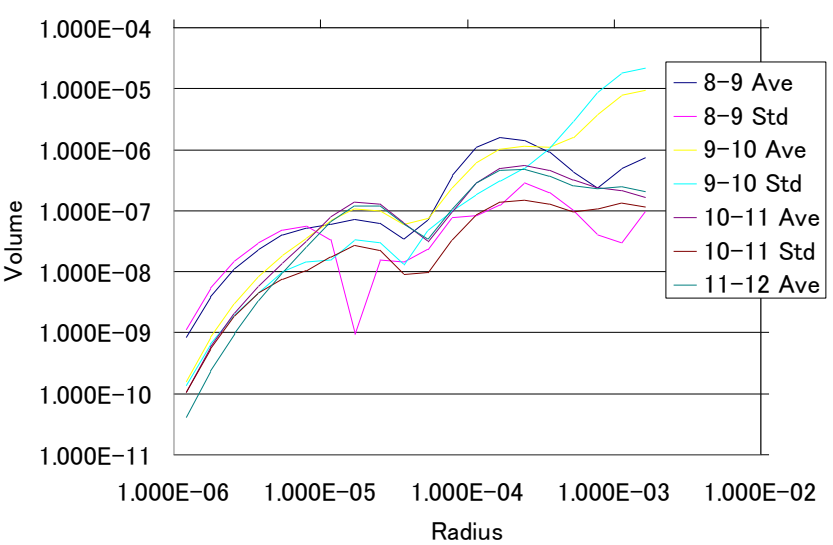

(d) Volume spectrum (Size distribution)

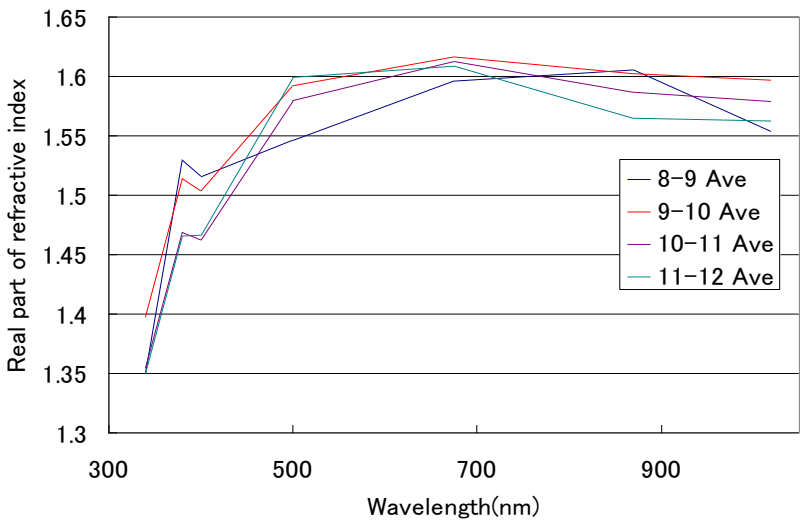

(e) Real part of refractive index

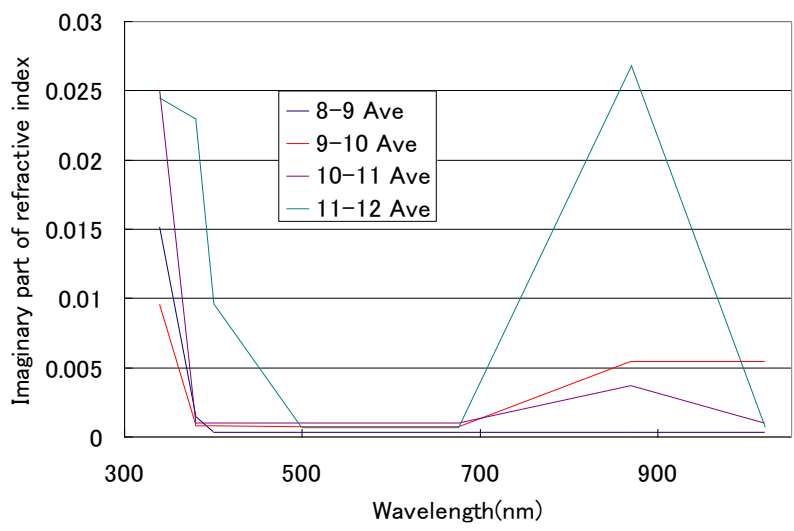

(f) Imaginary part of refractive index

Fig. 4. Atmospheric and surface characteristics of the test site at Roach Lake measured on December 32008.

Meanwhile those for Coyote Lake campaign are shown in Figure 5. Atmospheric optical depth for Coyote Lake campaign was very thin compared to Roach Lake campaign. In particular, Junge parameter for Coyote Lake campaign is twice much greater than that for Roach Lake campaign. This implies that small size of aerosol particles is dominant for Coyote Lake campaign in comparison to Roach Lake campaign. 


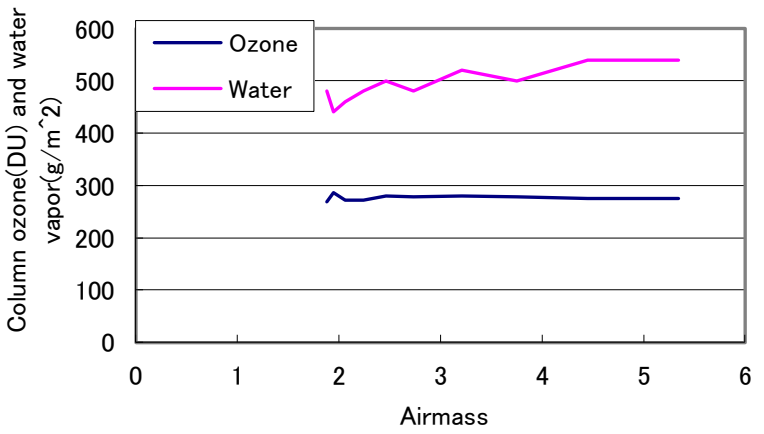

(a) Column ozone and water vapor

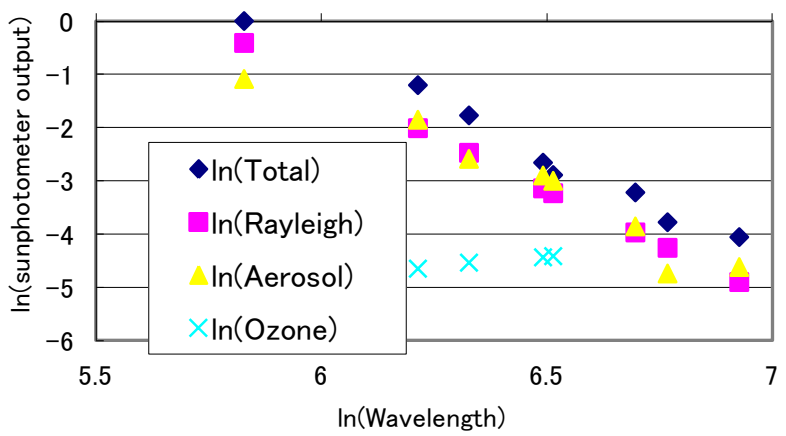

(b) Angstrome exponent and Junge parameter

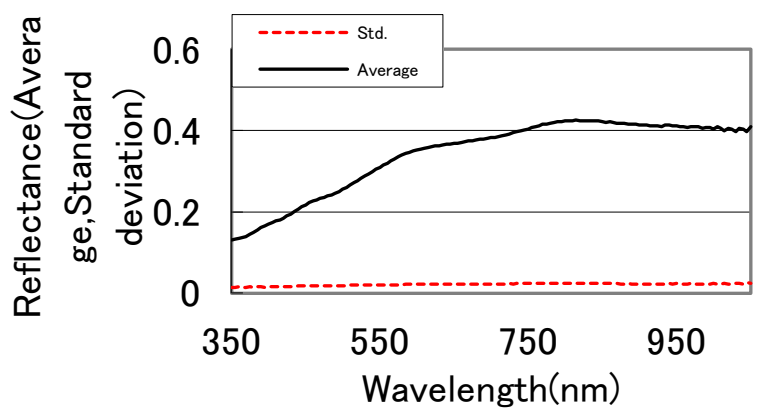

(c) Surface reflectance

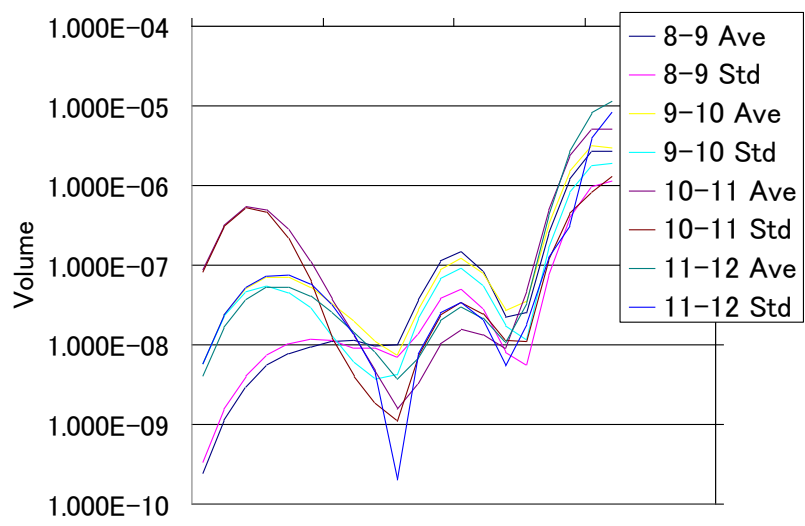

1.000E-06 1.000E-05 1.000E-04 1.000E-03 1.000E-02

Radius

(d) Volume spectrum (Size distribution)

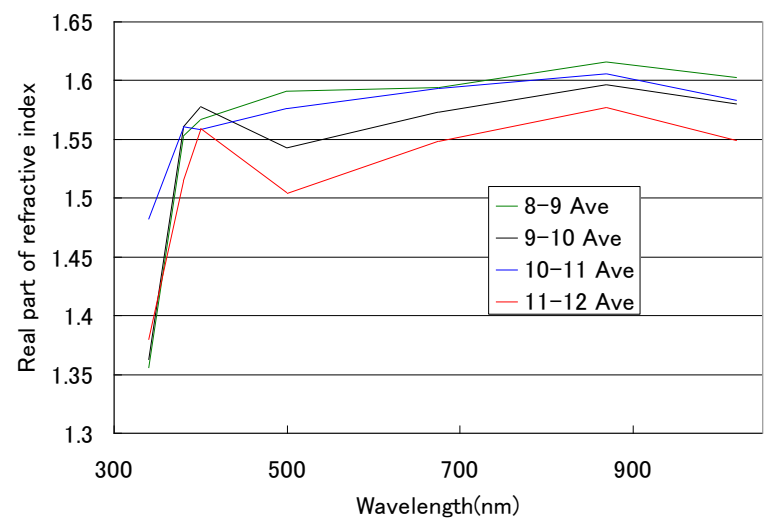

(e) Real part of refractive index

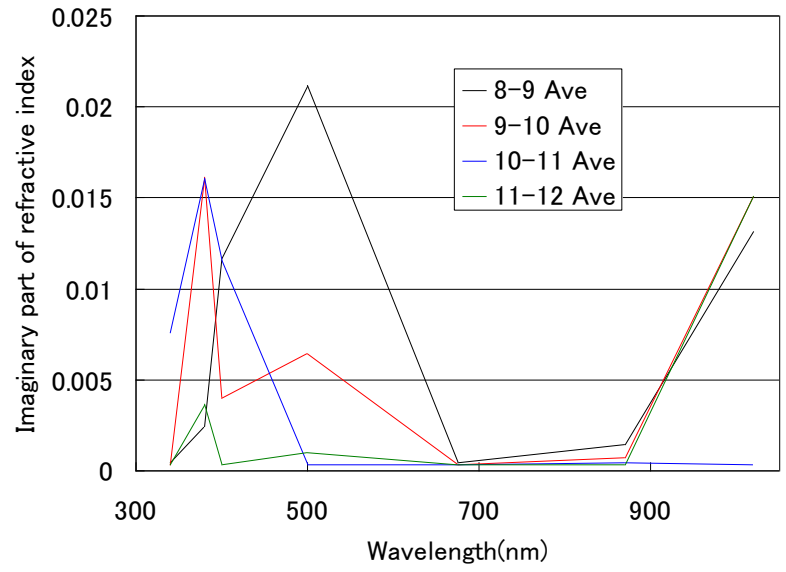

(f) Imaginary part of refractive index

Fig. 5. Atmospheric and surface characteristics of the test site at Coyote Lake measured on December 102008.

Refractive index and size distribution are estimated with skyradiometer data which allows measure solar direct, diffuse and aureole irradiance on the ground surface. Dr.Tsuchida and Dr.Kamei provided Skyradiometer data with their courtesy [Tsuchida and Kamei, 2009]. Using the modified skyrad.pack of software code, refractive index and size distribution are retrieved with these data. Although the original skyrad.pack provided by Dr.Nakajima (Nakajima et al., 2000) does not care about polarized radiance from the surface, the modified Arai-Ryo model takes $\mathrm{p}$ and $\mathrm{s}$ polarization of irradiance and radiance in the radiative transfer (Arai and Liang, 2005). On the other hand, measured scattering angle characteristics of Degree of Polarization (DP) are shown in Figure 6. Using curve-fitting algorithm of iterative method, most appropriate refractive index and size distribution (Junge parameter) is estimated. Through a comparison between estimated refractive index and Junge parameter by Arai-Ryo model with skyradiometer data and by curve fitting algorithm with seven scattering angles $(60,70,80,90,100,110,120)$ of $\mathrm{DP}$, it is found that both shows good coincidence (difference between both is within a range of $\pm 5 \%$. In accordance with the previous research, it is known that the estimation accuracy of refractive index and Junge parameter is approximately $6 \%$. $\pm 10 \%$ of refractive index and Junge parameter estimation accuracy 
causes $\pm 2 \%$ of TOA radiance estimation accuracy so that $6 \%$ of accuracy of refractive index and Junge parameter would causes below $2 \%$ of TOA radiance estimation accuracy.

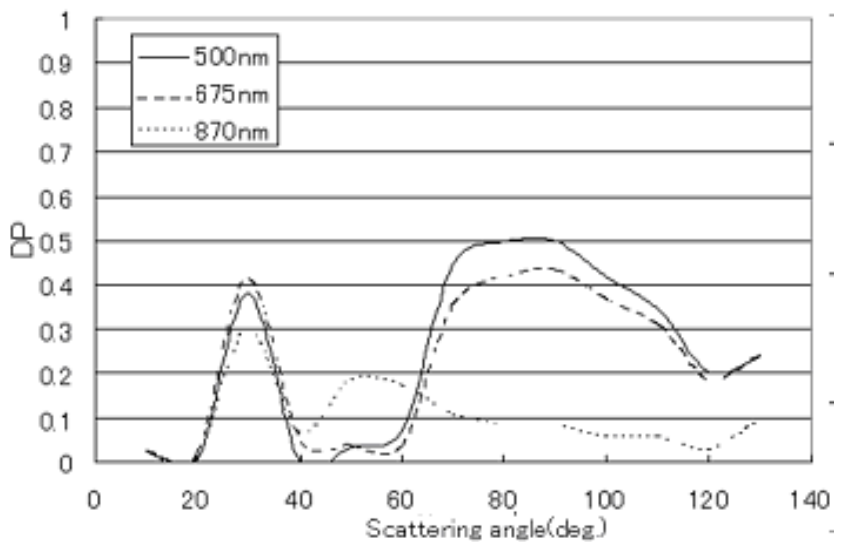

(a) Roach Lake campaign

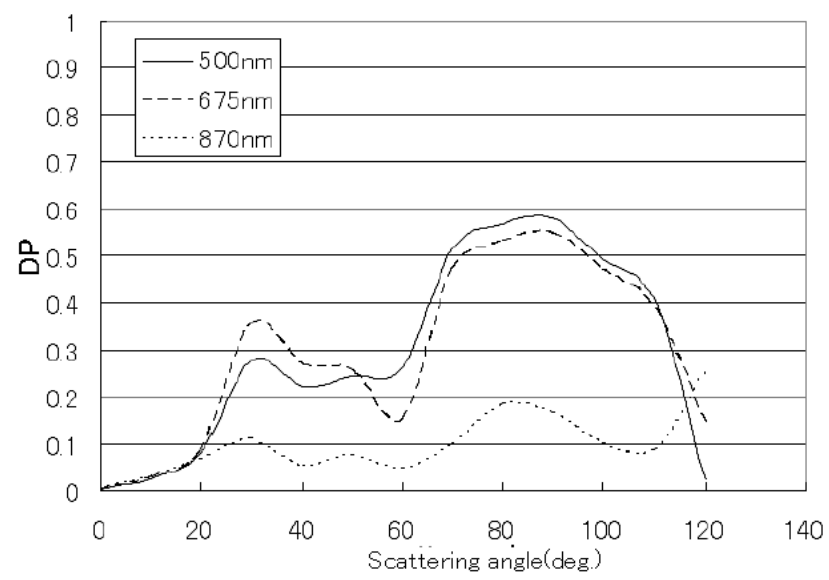

(b) Coyote Lake campaign

Fig. 6. DP measured for field campaigns at Roach Lake and Coyote Lake which were conducted on December 3 and 102008.

Using estimated refractive index and size distribution derived from skyradiometer data and DP data as well as surface reflectance, column ozone and water vapor, atmospheric pressure (Rayleigh scattering) TOA radiance is estimated based on MODTRAN. Table 2 shows the estimated refractive index and size distribution with skyradiometer data and DP data for Roach Lake and Coyote Lake campaigns. Both show a good coincidence, discrepancy of real part of refractive index ranges from -4.65 to $2.566 \%$, difference of imaginary part of refractive index ranges from -5.86 to $3.846 \%$, and discrepancy of Junge parameter ranges from 0.013 to $3.653 \%$, respectively.

Meanwhile Table 3 shows the estimated TOA radiance with refractive index and size distribution derived from DP data and skyradiometer data. Also both show a good coincidence, below $15.22 \%$ of discrepancy. In particular, discrepancy at the shorter wavelength, 560 and $660 \mathrm{~nm}$ of Bands 1 and 2 for Coyote Lake campaign is much greater than those for Band 3 for Coyote field campaign and Roach Lake campaign.
TABLE II. COMPARISON OF JUNGE PARAMETER AND REFRACTIVE INDEX DERIVED FROM SKYRADIOMETER DATA AND DP DATA

\begin{tabular}{|l|l|l|l|l|}
\hline & Method & Junge & Real & Imaginary \\
\hline $\begin{array}{l}\text { 08/12/03 } \\
\text { Roach }\end{array}$ & Skyradiometer & 3.372 & 1.582 & 0.0004 \\
\cline { 2 - 5 } & DP & 3.365 & 1.501 & 0.0003 \\
\hline $\begin{array}{l}08 / 12 / 10 \\
\text { Coyote }\end{array}$ & Skyradiometer & 5.213 & 1.574 & 0.0068 \\
\cline { 2 - 5 } & DP & 5.214 & 1.541 & 0.0066 \\
\hline
\end{tabular}

TABLE III. COMPARISON OF TOA RADIANCE DERIVED FROM SKYRADIOMETER DATA AND DP DATA

\begin{tabular}{|l|r|r|r|}
\hline 2008/12/3 & \multicolumn{1}{|c|}{ L_DP } & L_skyrad & \% difference \\
\hline B1(560) & 111.75 & 110.47 & 1.145 \\
\hline B2(660) & 114.4 & 113.65 & 0.656 \\
\hline B3N(810) & 95.2 & 94.84 & 0.378 \\
\hline B3B(810) & 94.58 & 94.56 & 0.021 \\
\hline 2008/12/10 & \multicolumn{1}{|c}{ L_DP } & L_skyrad & \% difference \\
\hline B1(560) & 109.08 & 92.48 & 15.22 \\
\hline B2(660) & 99.22 & 89.67 & 9.625 \\
\hline B3N(810) & 76.7 & 73.22 & 4.537 \\
\hline B3B(810) & 76.12 & 73.92 & 2.89 \\
\hline
\end{tabular}

This is caused by relatively large Junge parameter, small size of aerosol particles are greater than large size of those for Coyote Lake campaign. Except these, the discrepancy between two methods for estimation of TOA radiance with skyradiometer data and DP data is below $4.5 \%$. Due to the fact that aerosol optical depth increases in accordance with decreasing wavelength sharply for Coyote Lake field campaign, the discrepancy between estimated TOA radiance between two methods is greater than those in the longer wavelength regions. Also it is true that Junge parameter for Coyote Lake campaign is twice much greater than Roach Lake campaign. TOA radiance is sensitive to Junge parameter, in particular, greater Junge parameter regions as is shown in Figure 7 (which was derived from the field campaign which was conducted at Railroad valley on September 21 2008). In accordance with increasing of Junge parameter, the calculated TOA radiance is increased sharply. For these reasons, the discrepancy between two methods for Coyote Lake campaign is greater than that of Roach Lake.

\section{CONCLUSION}

The estimated refractive index and size distribution using the proposed DP based method shows a good coincidence with the estimated those by the conventional skyradiometer (POM01 which is manufactured by Prede Co. Ltd.), or aureole meter based method so that the proposed method does work well. The Junge parameter estimated by skyradiometer based method is derived from Angstrome exponent that is calculated with aerosol optical depth measured with skyradiometer while that by the proposed DP based method is derived from Angstrome exponent that is calculated with aerosol optical depth measured with polarized irradiance measuring instrument (MS720 which is manufactured by EKO Co. Ltd.). 

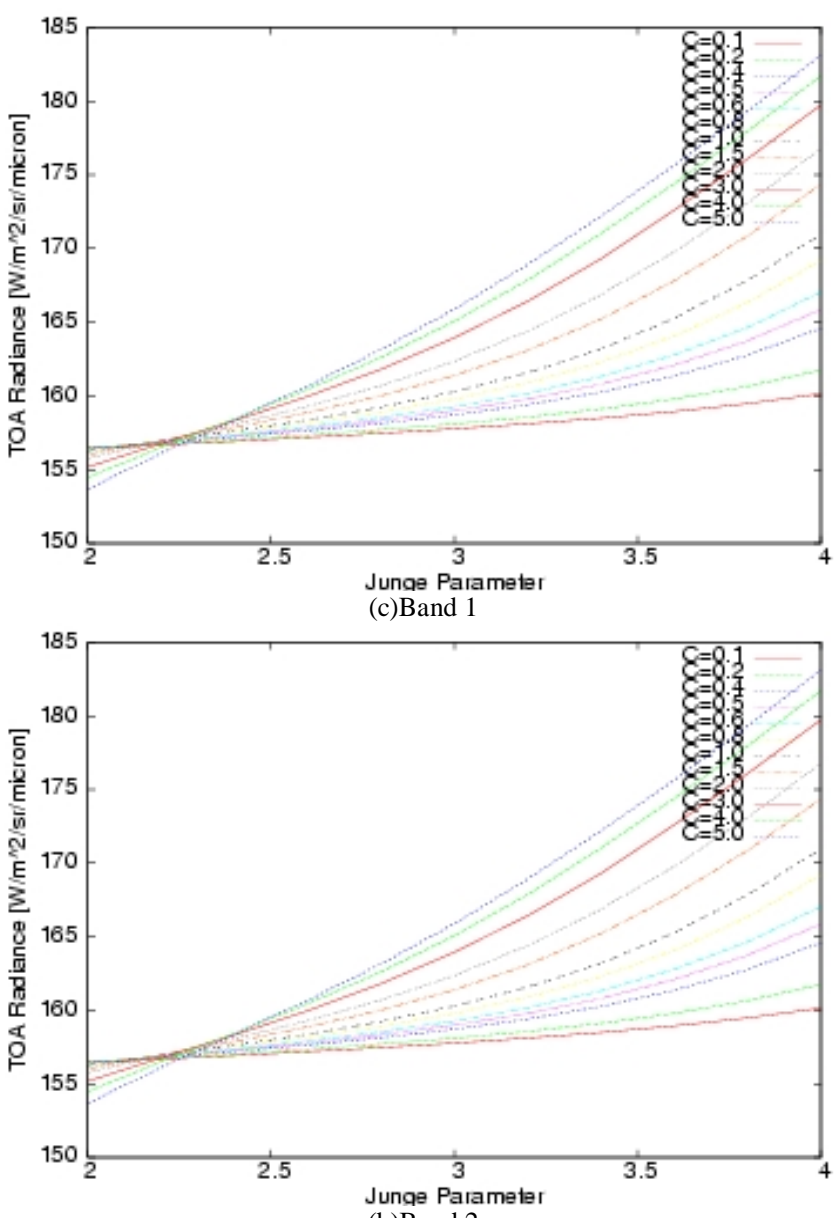

(b)Band 2

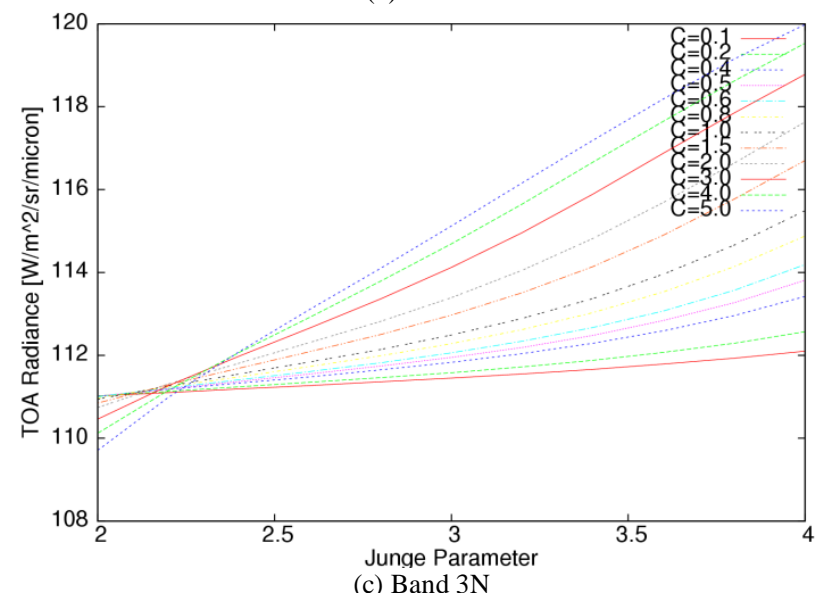

Fig. 7. Relation between TOA radiance and Junge parameter (Example of the calculated TOA radiance for the field campaign which was conducted at Railroad valley on September 212008 )

The difference between both is caused by the difference of gain/offset of the two instruments, POM-1 and MS720. On the other hand, the differences of estimated refractive index between skyradiometer based and the proposed DP based methods are mainly caused by the estimation methods, inversion of radiance to refractive index for skyradiometer based method while least square method minimizing the discrepancy between the actual and simulated DP at the seven different scattering angles based on MODTRAN.
The difference of TOA radiance derived from the proposed DP based method and the conventional skyradiometer based method is within the range of $1.2 \%$ for relatively high reflectance and comparatively thin aerosol optical depth as well as small Junge parameter case (relatively large aerosol particles are dominant) and is within the range of 2.9 to $15.2 \%$ for relatively low reflectance and comparatively thick aerosol optical depth as well as large Junge parameter case (relatively small aerosol particles are dominant). Due to the fact that $p$ and s polarized irradiance is relatively small for relatively high reflectance and comparatively thin aerosol optical depth as well as small Junge parameter case (relatively large aerosol particles are dominant), it is understandable.

It is obvious that skyradiometer and aureole meter is typically large and heavy in comparison to the polarized irradiance measuring instruments. It is possible to bring the polarized irradiance measuring instrument at anywhere easily. $\mathrm{p}$ and $\mathrm{s}$ polarized irradiance measurement at the seven different scattering angle takes around three minutes so that it has to be assumed that the atmosphere is stable for more than three minutes. $p$ and s polarized irradiance is sensitive to the surface reflectance so that it is recommendable to use the proposed method for widely homogeneous ground cover targets.

\section{ACKNOWLEDGMENT}

The author would like to thank Mrs. Yui Nishimura for her efforts through experiments and simulations.

\section{REFERENCES}

[1] Aoki, K., T. Takamura, and T. Nakajima, Aerosol optical properties measured by SKYNET sky radiometer validation network. Proc. of the 2nd EarthCARE Workshop, 133-134, 2005.

[2] Arai K., Preliminary assessment of radiometric accuracy for MOS-1 sensors, International Journal of Remote Sensing, 9, 1, 5-12, 1988.

[3] Arai, K., In-flight test site cross calibration between mission instruments onboard same platform, Advances in Space Research, 19, 9, 1317-1328, 1997.

[4] Arai K., Post Launch Calibration of ASTER with MODIS data, Proceedings of the 3rd Annual IR Calibration Symposium in Utah State University, 1992.

[5] Arai K., A.Ono and Y.Yamaguchi, Accuracy Assessment of the Interactive Calibration of ASTER/TIR with MODIS, Proceedings of the IGARSS'93, pp.1303-1305, 1993.

[6] Arai K., H.Fujisada, ASTER Level 1 WG, ATBD: Analytical Theoretical Basis Document for Level 1 Products, 1995.

[7] Arai K., and K.Thome, Error budget analysis of the reflectance based vicarious calibration for satellite-based visible to near infrared radiometers, Journal of the Japanese Society for Photogrammetry and Remote Sensing, 39, 1, 99-105, 2000.

[8] Arai K. and X.Liang, Method for the top of the atmosphere radiance estimation taking into account the polarization in down and up welling radiance calculations, Journal of the Japanese Society for Photogrammetry and Remote Sensing, 44, 3, 4-12, 2005.

[9] Arai and H.Tonooka, Radiometric performance evaluation of ASTER/VNIR, SWIR and TIR, IEEE Trans. on GeoScience and Remote Sensing, 43,12,2725-2732, 2005.

[10] Arai,K. and X.Liang, Characterization of aerosols in Saga city areas, Japan withy direct and diffuse solar irradiance and aureole observations, Advances in Space Research, 39, 1, 23-27, 2006.

[11] Arai, K., Vicarious calibration for solar reflection channels of radiometers onboard satellites with deserted area of data, Advances in Space Research, 39, 1, 13-19, 2006. 
[12] Arai, Atmospheric Correction and Residual Errors in Vicarious CrossCalibration of AVNIR and OCTS Both Onboard ADEOS, Advances in Space Research, 25, 5, 1055-1058, 1999.

[13] Barker, J.L., S.K. Dolan, et al., Landsat-7 mission and early results, SPIE, 3870, 299-311, 1999.

[14] Barnes, R.A., E.E.Eplee, et al., Changes in the radiometric sensitivity of SeaWiFS determined from lunar and solar based measurements, Applied Optics, 38, 4649-4664, 1999.

[15] Cosnefroy, H., M.Leroy and X.Briottet, Selection and characterization of Saharan and Arabian Desert sites for the calibration of optical satellite sensors, Remote Sensing of Environment, 58, 110-114, 1996.

[16] Folkman, M.A.,S.Sandor, et al., Updated results from performance characterization and calibration of the TRWIS III Hyperspectral Imager, Proc. SPIE, 3118-17, 142, 1997.

[17] Gellman, D.I., S.F. Biggar, et al., Review of SPOT-1 and 2 calibrations at White Sands from launch to the present, Proc. SPIE, Conf.No.1938, 118-125, 1993.

[18] Hagolle, O., P.Galoub, et al., Results of POLDER in-flight calibration, IEEE Trans. On Geoscience and Remote Sensing, 37, 1550-1566, 1999.

[19] Holben, B. N., et al., AERONET- A federated instrument network and data achieve for aerosol characterization, Remote Sens., 12, 1147-1163, 1991.

[20] Holben, B.N., and Coauthors, AERONET-A federated instrument network and data archive for aerosol characterization. Remote Sens. Environ., 66, 1-16. 1998.

[21] Lenoble, J., Edt. Radiative transfer in scattering and absorbing atmospheres: Standard computational procedures, A.Deepak Publishing Co.,Ltd.,

[22] Liang X. and K.Arai, Method for aerosol refractive index and size distribution with the solar direct, diffuse, aureole and polarization radiance, Journal of Remote Sensing Society of Japan, 25, 4, 357-366, 2005.
[23] Nakajima, T., M.Tanaka and T. Yamauchi, Retrieval of the optical properties of aerosols from aureole and extinction data, Applied Optics, 22, 19, 2951-2959, 1983.

[24] Ono.A., F.Sakuma, K.Arai, et al.,Pre-flight and Inflight Calibration for ASTER, Journal of Atmospheric and Ocean Technology, Vol.13, No.2, pp.321-335, Apr.,1996.

[25] Slater P., K.Thome, A.Ono, F.Sakuma, K.Arai, et al., Radiometric Calibration of ASTER, Journal of Remote Sensing Society of Japan, Vol.15, No.2, pp.16-23, June 1995.

[26] Thome, K., K. Arai, et.al., ASTER preflight and in-flight calibration and validation of level 2 products, IEEE Trans. on Geoscience and Remote Sensing, 36, 4, 1999.

[27] Thome, S.Schiller, J.Conel, K.Arai and S.Tsuchida, Results of the 1996 Earth Observing System vicarious calibration campaign at Lunar lake playa, Nevada (USA), Metrologia, 35, 631-638, 1998.

[28] Tsuchida, S. and A.Kamei, personal correspondence, 2009..

\section{AUTHORS PROFILE}

Kohei Arai, He received BS, MS and PhD degrees in 1972, 1974 and 1982, respectively. He was with The Institute for Industrial Science and Technology of the University of Tokyo from April 1974 to December 1978 also was with National Space Development Agency of Japan from January, 1979 to March, 1990. During from 1985 to 1987, he was with Canada Centre for Remote Sensing as a Post Doctoral Fellow of National Science and Engineering Research Council of Canada. He moved to Saga University as a Professor in Department of Information Science on April 1990. He was a councilor for the Aeronautics and Space related to the Technology Committee of the Ministry of Science and Technology during from 1998 to 2000 . He was a councilor of Saga University for 2002 and 2003. He also was an executive councilor for the Remote Sensing Society of Japan for 2003 to 2005 . He is an Adjunct Professor of University of Arizona, USA since 1998. He also is Vice Chairman of the Commission "A" of ICSU/COSPAR since 2008. He wrote 30 books and published 482 journal papers 